\title{
A Review on Gas-Liquid Reactions in Light Oil Sweetening: Kinetics and Reactor Design Aspects
}

\author{
Sudip K. Ganguly ${ }^{[1] *}$, Neetu Varun ${ }^{[1]}$, Sunil Kumar ${ }^{[1]}$, Praveen K. Khatri ${ }^{[1]}$, Suman L. Jain ${ }^{[1]}$, \\ Madhukar O. Garg ${ }^{[1]}$, Laura A. Pellegrini ${ }^{[2]}$
}

\begin{abstract}
Thiols in liquefied petroleum gas are undesirable due to their foul odor and corrosive nature. The process of removing these thiols is termed as sweetening. Metal phthalocyanines are reported to be the most effective sweetening catalyst. However, the solubility of metal phthalocyanine is low in aqueous medium. Thus, in an effort to further improve upon the existing catalysts, a novel cobalt phthalocyanine sulfonamide catalyst was developed. Laboratory and commercial evaluation of this catalyst showed enhanced activity as compared to a commercial catalyst with comparable stability. With proven higher

activity, comparable stability, design of grass root oxidizer using this catalyst is the next step. Design of oxidizers for an extractive sweetening process based on this catalyst in grass root refineries requires a rigorous kinetic model. The paper reviews the literature on sweetening kinetics and focuses on the concepts of design of laboratory reactors for reaction kinetics studies for such gas-liquid reactions. Laboratory reactor systems can be useful for accurate estimation of kinetic parameters which can then be used to design industrial reactors and predict their performance.
\end{abstract}

Keywords: Cobalt phthalocyanine, Gas-liquid reactions, Kinetics, Sweetening, Thiols

Received: June 16, 2014; revised: August 03, 2014; accepted: August 18, 2014

\section{Light Oil Sweetening}

\subsection{Process}

Liquefied petroleum gas (LPG) is often contaminated with acidic compounds such as $\mathrm{H}_{2} \mathrm{~S}, \mathrm{CoS}$, and thiols, which are highly odorous and corrosive in nature. The $\mathrm{H}_{2} \mathrm{~S}$ and $\mathrm{CoS}$ are usually removed in an amine pretreatment unit, whereas thiols are extracted downstream by caustic in a sweetening unit [1-4]. The extractive sweetening process involves two stages, starting with extraction and culminating with oxidation. The lighter mercaptans are first extracted by caustic solution forming water and sodium mercaptide salts as shown in Eq. (1).

$2 \mathrm{RSH}_{\text {oil }}+2 \mathrm{NaOH}_{\mathrm{aq}} \rightarrow 2 \mathrm{NaSR}_{\mathrm{aq}}+2 \mathrm{H}_{2} \mathrm{O}_{\mathrm{aq}}$

In the second stage, shown in Eq. (2), these salts (NaSR) are oxidized by air injection in the presence of a catalyst, to an organic disulfide (RSSR). This organic disulphide phase separates by gravity (separator) from the aqueous caustic solution. After decantation of disulfides, the regenerated lean caustic solution is recirculated back to the top of the extractor to continue extracting mercaptans $[1,2,5-10]$.

$2 \mathrm{NaSR}_{\mathrm{aq}}+\mathrm{H}_{2} \mathrm{O}_{\mathrm{aq}}+0.5 \mathrm{O}_{2 \mathrm{aq}} \rightarrow 2 \mathrm{NaOH}_{\mathrm{aq}}+\mathrm{RSSR}_{\mathrm{oil}}$
The overall reaction is

$2 \mathrm{RSH}_{\text {oil }}+0.5 \mathrm{O}_{2, \mathrm{aq}} \stackrel{\mathrm{NaOH}, \text { catalyst }}{\longrightarrow} \mathrm{RSSR}_{\text {oil }}+\mathrm{H}_{2} \mathrm{O}_{\mathrm{aq}}$

The catalyst plays an important role in the oxidation of mercaptides to disulphides. Thiol oxidation mechanism in the presence of transition metal complexes was studied by Wallace et al. [11]. A series of transition metal pyrophosphates were investigated. The overall order of pyrophosphates activity was reported to be $\mathrm{Co}>\mathrm{Cu}>\mathrm{Ni}>\mathrm{Fe}$. Ligands like phosphomolybdate, phosphotungstate, phosphate, and phthalocyanines were also tried with cobalt as the transition metal. Pyrophosphates and phthalocyanines were reported to be the most promising.

\footnotetext{
[1] Prof. Sudip K. Ganguly (corresponding author), Neetu Varun, Sunil Kumar, Dr. Praveen K. Khatri, Dr. Suman L. Jain, Dr. Madhukar O. Garg CSIR-Indian Institute of Petroleum, Dehradun, 248005, India. E-Mail: sganguly@iip.res.in

${ }^{[2]}$ Prof. Laura A. Pellegrini Dipartimento di Chimica, Materiali e Ingegneria Chimica "Giulio Natta", Politecnico di Milano, Italy.
} 
Basu et al. [6] and Sorokin [12] reported metal phthalocyanines using cobalt, vanadium, iron, manganese, and molybdenum as one of the most effective catalyst for oxidation of thiols. As metal phthalocyanines have limited solubility in aqueoous medium, their activity is low in aqueous medium. Hence, for improved catalytic activity, derivatives like sulphonated and carboxylated metal phthalocyanines were developed as catalysts for sweetening of lighter petroleum fractions. Until recently, cobalt phthalocyanine disulphonate was a commonly used commercial catalyst in sweetening of LPG and lighter petroleum fractions. The dusty nature of this catalyst caused handling problems. To improve this, the tetrasulphonate form of the catalyst was developed which was highly soluble but had lower activity. Accordingly, in an effort to develop novel sweetening catalysts, the attention was drawn towards the amide group $[13,14]$. Thus, a novel cobalt phthalocyanine sulphonamide catalyst $(\mathrm{CoPcS})$ higher in activity and of comparable stability when compared with commercial catalyst was developed $[15,16]$.

\subsection{Gas Liquid Reactions}

The oxidizer in the sweetening process carries out oxidation of the extracted mercaptides to disulphides in a gas-liquid reaction system governed both by factors connected with transfer of oxygen from the gas to the liquid phase and by factors associated with the chemical reaction $[17,18]$. Gas-liquid reactions are broadly classified based on the Hatta number $(\gamma)$ into fast, slow, and very slow reactions. It is a dimensionless number signifying the ratio of maximum possible conversion to maximum diffusional transport of the reactant in the film. For fast reactions, $\gamma>2$, for slow reactions, $\gamma$ ranges from 0.02 to 2 , whereas for very slow reactions, $\gamma<0.02$ [19]. In the case of thiol oxidation for uncatalysed or catalysed reactions with low catalyst concentrations, $\gamma$ was estimated to fall in the range of 0.05 to 1.758 and, hence, it is a slow reaction [20-23]. In such cases, reaction happens both in the film and bulk. In the case of airwater system, liquid mass transfer is controlling [24]. Therefore, transport of oxygen from gas phase to liquid phase is controlled by the liquid mass transport term. To be able to determine the true kinetics representing industrial conditions, it is necessary to establish hydrodynamics which ensures maximum transport of oxygen to the bulk. Substantial literature is available on mass transfer effects and reaction kinetics studies on thiol oxidation by Van de Vusse [20], Pal and Sharma [25], Leitao and Rodrigues [21], Xia et al. [22, 26, 27], Ganguly et al. [16, 28-31], and Ehsani et al. [23,32]. They studied the mass transfer, kinetics, and mechanism of catalytic co-oxidation of pure and mixed thiols (ethanethiol, iso-propanethiol, 1-butanethiol, 1-octanethiol, and 2-methyl-2-propanethiol) in gas-liquid and gas-solid-liquid systems. However, literature focused on laboratory reactor design aspects for overcoming transport limitations for studying sweetening kinetics is limited. The aim of the article is to discuss and bring out the procedures for determining the intrinsic kinetics of oxidation of thiols in gasliquid systems by overcoming the hydrodynamic limitations.

\subsection{Mechanistic Kinetics}

Preliminary kinetics studies have been conducted to establish the rate law for thiol oxidation kinetics for the aforementioned catalyst using mechanistic approach $[29,30]$. The feed mercaptide concentration to an oxidizer in Indian refineries generally falls in the range of $0.05-0.15 \mathrm{~mol} \mathrm{~L}^{-1}$. 1-Butanethiol was used as the representative thiol. The kinetic studies were conducted with a feed RSH concentration of $0.138 \mathrm{~mol} \mathrm{~L}^{-1}$ of 1-butanethiol at 15,30 and $45^{\circ} \mathrm{C}$ to cover industrial process conditions. To explain the observed behavior of rate curves obtained during the studies, a mechanism was adopted from Wallace et al. [11]. In this mechanism, it was assumed that catalytic oxidation occurs via an anion radical mechanism in which thiol radical was produced through electron transfer from thiolate anion to trivalent cobalt in the catalyst. The thiolate anions produced by ionisation of thiols species are responsible for subsequent thiol oxidation. Pseudo-steady-state kinetics was assumed for the rates of formation of adducts. Considering the overall stoichiometry, a mechanistic rate law representing double substrate Michaelis-Menten rate expression was obtained:

$$
\begin{aligned}
& -r_{\mathrm{RSH}}= \\
& \frac{k_{2} k_{3} k_{4}[\mathrm{cat}]_{\mathrm{tot}}\left[\mathrm{C}_{4} \mathrm{H}_{9} \mathrm{SH}\right]\left[\mathrm{O}_{2}\right]}{\left[k_{-2}\left(k_{4}+k_{-3}\right)+k_{3} k_{4}\left[\mathrm{O}_{2}\right]+k_{2}\left(k_{4}+k_{-3}\right)\left[\mathrm{C}_{4} \mathrm{H}_{9} \mathrm{SH}\right]+k_{2} k_{3}\left[\mathrm{C}_{4} \mathrm{H}_{9} \mathrm{SH}\right]\left[\mathrm{O}_{2}\right]\right]}
\end{aligned}
$$

In industrial conditions excess air is present in the oxidizer. Hence, for a constant air flowrate, Eq. (4) simplifies to a single substrate Michaelis-Menten rate expression:

$-r_{\mathrm{RSH}}=\frac{k_{1}^{\mathrm{I}}[\mathrm{cat}]_{\mathrm{tot}}\left[\mathrm{C}_{4} \mathrm{H}_{9} \mathrm{SH}\right]}{\left[K_{\mathrm{M}}+\left[\mathrm{C}_{4} \mathrm{H}_{9} \mathrm{SH}\right]\right]}$

For a relatively high $K_{M}$ (Michaelis-Menten constant) as compared to the feed mercaptide concentration $\left(C_{\mathrm{RSH}}\right)$, the rate expression in Eq. (5) is further simplified to a first order rate law which explained the rate data obtained in previous studies on thiol oxidation kinetics studies reasonably well $[29,30]$.

$-r_{\mathrm{RSH}}=k_{\mathrm{eff}}[\mathrm{cat}]_{\mathrm{tot}} C_{\mathrm{RSH}}=k_{\mathrm{cat}} C_{\mathrm{RSH}}$

where:

$k_{\text {eff }}=\frac{k_{1}^{\mathrm{I}}}{K_{\mathrm{M}}}$

The rate law derived in Eqs. (4) and (5) compares well with kinetic studies conducted by Xia et al. [22] using phthalocyanine based catalysts for thiol oxidation.

\section{Discussions on Gas-Liquid Reactor Design}

Discussions are presented to evolve an appropriate design of a laboratory reactor by establishing hydrodynamics, which will help in determining intrinsic kinetic parameters for the catalyst 
useful for industrial reactor design, and prediction of performance with a reasonable accuracy.

\subsection{Hydrodynamic Aspects}

$\gamma$ indicates the sweetening reaction to be slow. The reaction is, hence, expected to take place both in the film and the bulk. Moreover, the reaction will happen in the bulk after transport of oxygen through the film. Therefore, design of the laboratory reactor system should be such that it ensures maximum transfer of oxygen to the liquid containing mercaptides. In case of air-water system, the liquid film resistance is controlling [24]. The liquid side mass transport is represented by $S K_{\mathrm{L}} \mathrm{O}^{\mathrm{i}}$ as indicated in Eq. (7). The objective is to maximize this mass transport of oxygen by designing a suitable laboratory reactor with required hydrodynamics.

$S K_{\mathrm{L}}\left(\mathrm{O}^{\mathrm{i}}-\mathrm{O}^{\mathrm{L}}\right) \propto S K_{\mathrm{L}} \mathrm{O}^{\mathrm{i}}$

The solubility of oxygen at the air-water interface, $\mathrm{O}^{\mathrm{i}}$, is influenced by the partial pressure, $p_{\mathrm{O}_{2}}$, which is determined by composition of the gas as well as the total gas pressure, $P_{\mathrm{t}}$. The relationship [33] between these parameters is expressed in Eq. (8).

$\mathrm{O}^{\mathrm{i}}=\frac{p_{\mathrm{O}_{2}}}{\mathrm{H}}$

This physical mass transport can also be correlated with the agitator power consumption, $P_{\mathrm{c}}$, and the superficial gas velocity, $v_{\mathrm{g}}$, as reported by Cooper et al. [34] and Van de Vusse [20].

Therefore,

$S K_{\mathrm{L}} \mathrm{O}^{\mathrm{i}} \propto\left(P_{\mathrm{c}} / V\right)\left(v_{\mathrm{g}}^{2 / 3}\right) p_{\mathrm{O}_{2}}$

Considering geometric scaling, physical mass transport may be interpreted in terms of the mercaptan oxidation rate $(Q)$,

$S K_{\mathrm{L}} \mathrm{O}^{\mathrm{i}} \propto\left(P_{\mathrm{c}} / V\right)\left(Q^{2 / 3} / V^{4 / 9}\right) p_{\mathrm{O}_{2}}$

Eq. (10) may also be expressed in terms of the oxygen/air flowrate $\left(Q_{\mathrm{F}}\right)$, which depends on $Q$,

$S K_{\mathrm{L}} \mathrm{O}^{\mathrm{i}} \propto\left(P_{\mathrm{c}} / V\right)\left(Q_{\mathrm{F}}^{2 / 3} / V^{4 / 9}\right) p_{\mathrm{O}_{2}}$

The oxygen/air flowrate needs to be maintained at much higher values than what is required stoichiometrically, to ensure presence of excess oxygen. Therefore, for given experimental conditions comprising of mercaptan loading, $Q$ molar air flowrate, $Q_{\mathrm{F}}$ reactor volume, $V$, and oxygen partial pressure, $p_{\mathrm{O}_{2}}$, the dependence may be simplified to the following expression.

$S K_{\mathrm{L}} \mathrm{O}^{\mathrm{i}} \propto f\left(P_{\mathrm{c}}\right)$

Power requirements for an agitated sparged contactor have been reported by researchers [35-42]. One such correlation proposed by Michel and Miller [36] is expressed in Eq. (13). In general, $P_{\mathrm{c}}$ is smaller than $P_{\mathrm{o}}$.

$P_{\mathrm{c}}=0.812\left(\frac{P_{\mathrm{o}}^{2} N d^{3}}{Q_{\mathrm{G}}^{0.56}}\right)^{0.45}$ where:

$P_{\mathrm{o}}=N_{\mathrm{p}} N^{3} d^{5} \rho_{\mathrm{L}}$

The power number, $N_{\mathrm{P}}$ is a dimensionless number used for quantifying the power requirements of an impeller under ungassed conditions for mixing of a fluid system. It depends on impeller Reynolds number and system geometry [43]. $N_{\mathrm{P}}$ for different impeller designs have been reported by Nienow and Miles [44].

Hence,

$S K_{\mathrm{L}} \mathrm{O}^{\mathrm{i}} \propto f(N)$

For a given set of operating conditions, the relationship in Eq. (14) points out the need to study the dependence of physical mass transfer on $N$ over a broad range. The transport of oxygen to the liquid phase may be experimentally monitored in terms of dissolved oxygen concentration, $\mathrm{O}^{\mathrm{L}}$. The critical speed, $N_{c}$, can be determined once $\mathrm{O}^{\mathrm{L}}$ reaches a saturation value ensuring maximum possible transfer of oxygen to the liquid phase at the given experimental conditions. The kinetics should be studied at $N>N_{\mathrm{c}}$ conditions, ensuring hydrodynamic conditions for maximum oxygen transport to the liquid reaction mixture so that it meets the criterion of the rate law in Eq. (6) and intrinsic kinetics may be established.

\subsection{Gas-Liquid Reaction Aspects}

Here, sufficient availability of oxygen in liquid bulk is considered due to hydrodynamic conditions established as per procedures mentioned in the hydrodynamics section. The film theory is used to explain the transport combined with chemical reaction to derive the overall gas-liquid reaction rate. A reference scheme depicting the mass transfer and reaction process in the gas, film, and bulk liquid is shown in Fig. 1. The partial differential equation, which holds for the diffusion process combined with chemical reaction for $\mathrm{RSH}$ component in the film, may be expressed as shown in Eq. (15).

$D_{T} \frac{\partial^{2} C_{\mathrm{RSH}}}{\partial z^{2}}+r_{\mathrm{RSH}}=\frac{\partial C_{\mathrm{RSH}}}{\partial t}$

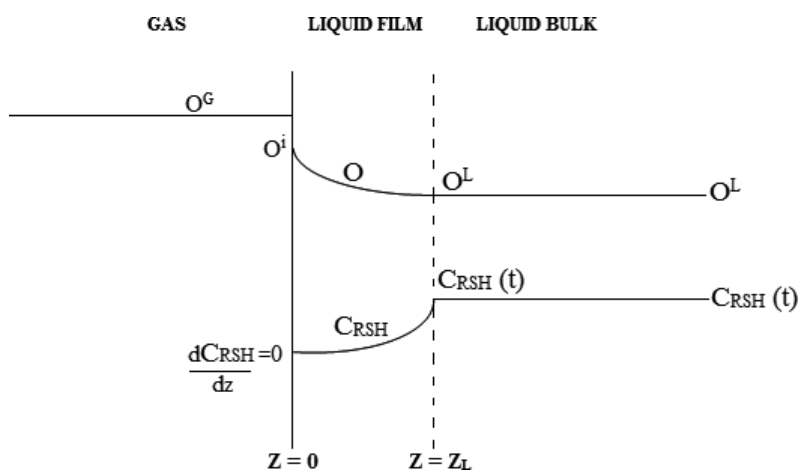

Figure 1. Reference scheme depicting mass transfer with reaction in light oil sweetening. 
Considering negligible accumulation of mercaptans within the infinitesmal film, the equation is simplified to an ordinary differential equation [45] as shown in Eq. (16).

$D_{T} \frac{\mathrm{d}^{2} C_{\mathrm{RSH}}}{\mathrm{d} z^{2}}=-r_{\mathrm{RSH}}$

\section{Boundary Conditions}

The boundary conditions pertaining to the reference scheme in Fig. 1 for the solution of Eq. (16) are:

$$
\begin{aligned}
& \frac{\mathrm{d} C_{\mathrm{RSH}}}{\mathrm{d} z}=0, \mathrm{O}=\mathrm{O}^{\mathrm{i}} \text { for } z=0 ; t>0 \\
& C_{\mathrm{RSH}}=C_{\mathrm{RSH}}(t), \mathrm{O}=\mathrm{O}^{\mathrm{L}} \text { for } z=z_{\mathrm{L}} ; t>0
\end{aligned}
$$

Hydrodynamic conditions established in the laboratory reactor ensures maximum oxygen transport to liquid at high stirrer speed $\left(N>N_{\mathrm{c}}\right)$ leading to minimum $z_{\mathrm{L}}$ and therefore the approximation in Eq. (17).

$\mathrm{O}^{\mathrm{i}} \sim \mathrm{O}^{\mathrm{L}}$

As explained in mechanistic kinetics section in Eq. (6), when excess oxygen is present, the reaction rate is independent of oxygen concentration and is proportional to mercaptan concentration. The solution of the equation gives the overall reaction rate $R(t)$ at a given time, $t>0$.

$$
\begin{aligned}
R(t)= & S \sqrt{k_{\mathrm{cat}} D_{T}} \tanh (\gamma) C_{\mathrm{RSH}}(t) \\
& +k_{\text {cat }}\left(1-S z_{\mathrm{L}}\right) C_{\mathrm{RSH}}(t)
\end{aligned}
$$

where:

$\gamma=z_{\mathrm{L}} \sqrt{\frac{k_{\mathrm{cat}}}{D_{T}}}$

$C_{\mathrm{RSH}}(t)$ represents bulk concentration and may lie between 0 and $C_{\mathrm{RSH}}^{0}$ for $\mathrm{z}>\mathrm{z}_{\mathrm{L}}$ with $\mathrm{O}=\mathrm{O}^{\mathrm{L}}$ at any given $t>0$. The overall reaction rate $R(t)$ in Eq. (18) for mass transfer combined with a chemical reaction consists of the combination of film and bulk terms. The first term represents the transport and reaction involved in the film and the second term represents the reaction term in the bulk. On rearrangement, the expression in Eq. (19) is obtained.

$R(t)=\left[S \sqrt{k_{\mathrm{cat}} D_{T}} \tanh (\gamma)+k_{\mathrm{cat}}\left(1-S z_{\mathrm{L}}\right)\right] C_{\mathrm{RSH}}(t)$

The effect of film term on the overall reaction rate may be neglected if the magnitude of $\gamma$ is reduced. This can be achieved by reducing the film thickness by generating a large number of small bubbles with a suitable sparger and impeller design, and by maintaining stirrer speeds of $N>N_{\mathrm{c}}$, as explained in the hydrodynamics section. In addition to this, the reactions may need to be carried out at low temperatures and low catalyst concentrations. Therefore, maintaining experimental conditions such as high stirrer speed, low temperature, and low catalyst dosage, $\gamma$ can be significantly reduced $(\gamma<<1)$, simplifying Eq. (19) to Eq. (20).

$R(t)=k_{\mathrm{cat}} C_{\mathrm{RSH}}(t)=-r_{\mathrm{RSH}}$

\subsection{Laboratory Reactor Design}

Considering the reactor design aspects, laboratory reactor system for oxidation of thiols should preferably be done in an agitated semi-batch reactor ensuring excess and continuous flow of oxygen/air through a sparged system. The stirred sparged semi-batch reactor has other advantages such as simplicity in design, compactness, and homogeneous mixing due to agitation leading to good temperature control that are essential for kinetic studies. Contacting of gas-liquid is dependent on the interfacial area per unit reactor volume, $S$ of the system. $S$ in turn depends on gas hold up, $\varepsilon_{\mathrm{g}}$, and bubble diameter, $d_{\mathrm{BM}}$, as shown in Eq. (21). It is evident that significant $\varepsilon_{\mathrm{g}}$ and small $d_{\mathrm{BM}}$ are desirable as it leads to increased $S$. Gas hold-up is influenced by $v_{\mathrm{g}}$ and $P_{\mathrm{c}}$. Similarly, high impeller speed results in lower $z_{\mathrm{L}}$ leading to higher $K_{\mathrm{L}}$ values. All this is helpful for maximisation of the volumetric mass transfer coefficient, $K_{\mathrm{L}} S$, which is essential for maximizing the transport of oxygen from gas to liquid phase. Maximisation of $K_{\mathrm{L}} S$ may be achieved in a reactor by designing a suitable sparger and impeller geometry.

$S=\frac{6 \varepsilon_{g}}{d_{\mathrm{BM}}}$

There are many reports on the performance of various sparger types like pipe, ring, concentric, conical, and disc. Ring type spargers have been reported to produce highest fractional $\varepsilon_{\mathrm{g}}$ and eliminate impeller flooding $[46,47]$. The effect of the sparger material has also been reported in the literature. Chakraborty et al. [48] reported ceramics to be one of the most effective materials resulting into higher $\varepsilon_{\mathrm{g}}$. The effect of the sparger ring diameter $s$ has also been studied and found that spargers with $0.45 d, 0.80 d, 1.40 d$, and $2.0 d$ dimensions are the most effective ones, where $d$ represents impeller diameter [46, 49-52]. The effect of sparger location has also been reported in the literature. It has been found that spargers located below impeller with smaller orifice size are the most effective [50-53]. The diagram of a ring sparger is shown in Fig. 2. For this system of alkaline aqueous phase of $13-15 \mathrm{wt} \%$ strength, viscosity is expected to fall in the range of 0.93 to $2.32 \mathrm{cP}$ [10]. Holland and Chapman [54] recommend a propeller or a flat blade turbine impeller for such applications. The distance between

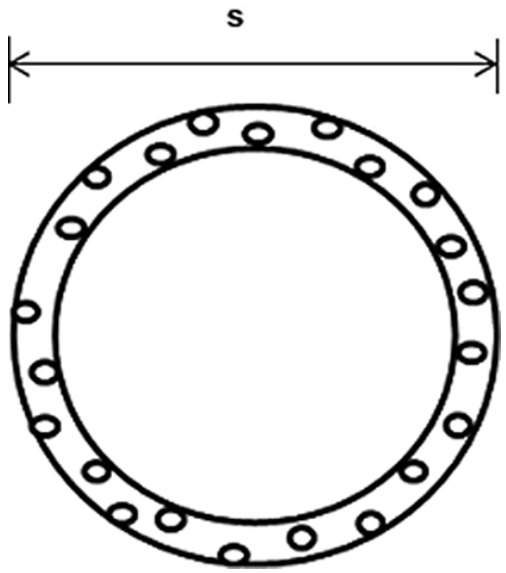

Figure 2. Diagram of a ring type sparger. 
impeller and sparger also plays an important role. It has been reported that impellers placed near to spargers generate smaller bubble sizes leading to lower terminal velocity, $v_{\mathrm{t}}$ with higher $\varepsilon_{\mathrm{g}}$ $[47,50,53,55]$. The diagram of a propeller type and a flat blade turbine type impeller are shown in Fig. 3 and 4, respectively. The use of baffles is also necessary for proper distribution of the gas and to avoid the formation of vortex at the free surface of the liquid [46]. The probable design of the reaction vessel, along with the relative dimensions of sparger, impeller, and baffles for achieving quality mixing for kinetic studies is suggested based on the reactor design aspects discussed earlier and recommendations of various researchers $[46,49,54,56,57]$, is shown in Fig. 5.

\subsection{Experimental Conditions for Reaction Rate Determination}

As explained in the gas liquid reaction section, for estimation of intrinsic kinetics, $\gamma$ needs to be maintained significantly low. In order to maintain low $\gamma$, it is recommended to conduct the experiments at temperatures $15-30{ }^{\circ} \mathrm{C}$ with catalyst concentrations in the range of $5-25 \mathrm{ppm}$ and the stirrer speed $N>N_{\mathrm{c}}$. The feed thiol concentration may be varied in the range of $0.05-0.15 \mathrm{~mol} \mathrm{~L}^{-1}$ and the pressure $P_{\mathrm{t}}$ may be varied from 1 to $7 \mathrm{~atm}$ to represent industrial conditions. The stirred semi-batch sparged reactor was specifically selected for its advantages, such as simplicity in design, compactness, and homogeneous mixing

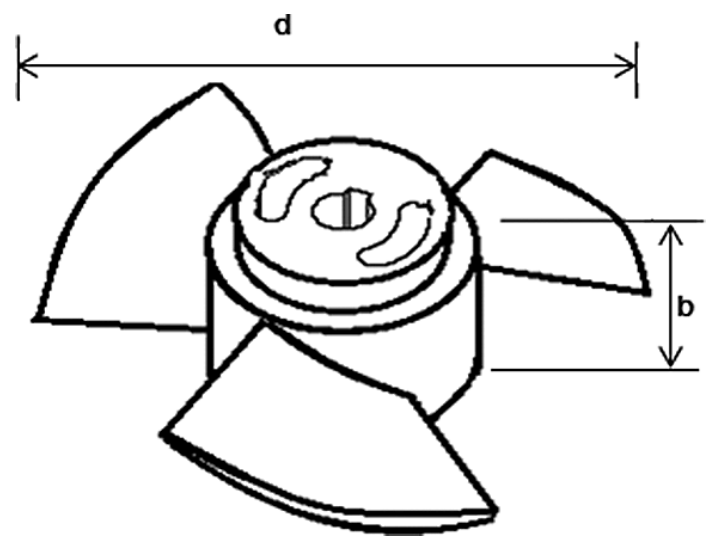

Figure 3. Diagram of a propeller-type impeller.

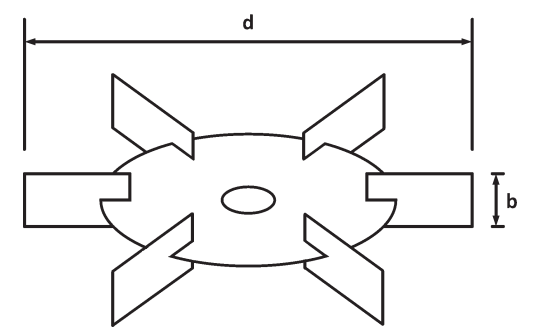

Figure 4. Diagram of a 6-blade flat-blade turbine-type impeller.

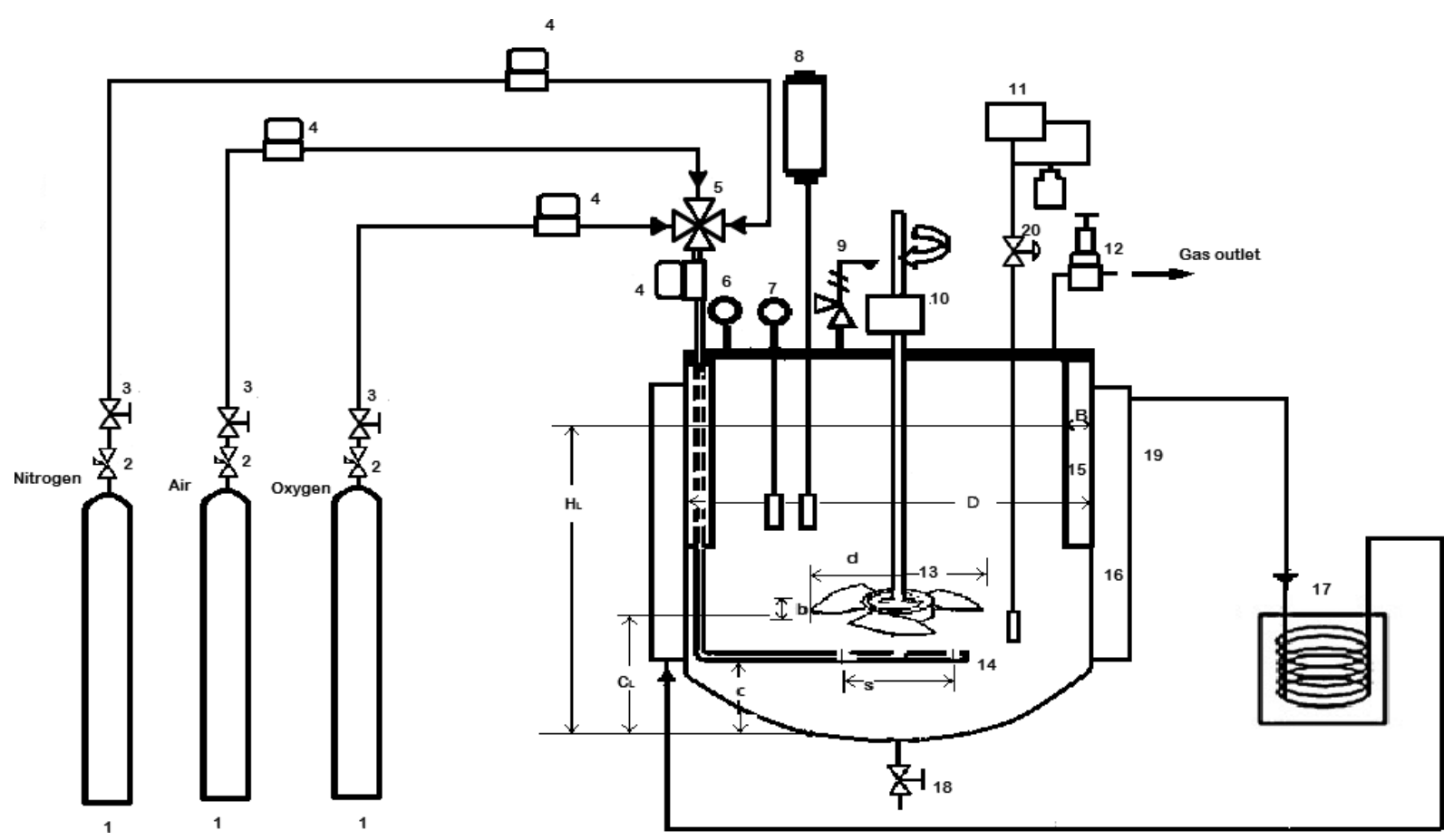

Figure 5. Experimental set-up. Components: (1) gas cylinders; (2) pressure regulator valves; (3) valves; (4) mass flow controllers; (5) fourway valve; (6) pressure indicator; (7) temperature indicator; (8) D.O. analyzer; (9) safety relief valve; (10) motor; (11) sampling system; (12) back pressure regulator; (13) impeller; (14) sparger; (15) baffles; (16) reactor jacket; (17) thermostatic water bath; (18) product outlet; (19) reactor vessel; (20) isolation valve. Dimensional ratios: $B / D=1 / 12 ;(b / d)=1.5 ; H_{L} / D=1 ; d / D=1 / 3 ; C_{L} / H_{L}=1 / 3 ; s / d=0.45-2$. 
leading to good temperature control, that are essential for kinetic studies. Experimental conditions mentioned here shall ensure that mass transfer resistance is minimum so that intrinsic kinetics could be determined. Mole balance in terms of RSH in a semi-batch reactor may be expressed as in Eq. (22).

$\frac{\mathrm{d} N_{\mathrm{RSH}}}{\mathrm{d} t}=F_{\mathrm{RSH}}^{\mathrm{in}}-F_{\mathrm{RSH}}^{\mathrm{out}}+r_{\mathrm{RSH}} V$

RSH inflow and outflow to/from the reactor will not be present, hence, considering constant volume system, RSH mole balance is simplified to Eq. (23).

$-r_{\mathrm{RSH}}=-\frac{\mathrm{d} C_{\mathrm{RSH}}}{\mathrm{d} t}$

The reaction mixture samples needs to be collected at time intervals and the measured concentrations are to be correlated with a polynomial [31], as shown in Eq. (24). Thiol oxidation kinetics may therefore be systematically studied as a function of feed mercaptide concentration, $C_{\mathrm{RSH}}$, catalyst concentration $\left([\mathrm{cat}]_{\text {tot }}\right)$, temperature $(T)$, and oxygen partial pressure $\left(p_{\mathrm{O}_{2}}\right)$ within the prescribed range of parameters for maintaining low $\gamma$ for validity of Eq. (20).

$C_{\mathrm{RSH}}(t)=a_{1}+b_{1} t+c_{1} t^{2}$

Considering Eq. (20) and (23), intrinsic kinetic parameters may be determined by using Eq. (25)

$k_{\mathrm{cat}}=\frac{-\left(b_{1}+2 c_{1} t\right)}{\left(a_{1}+b_{1} t+c_{1} t^{2}\right)}$

\subsection{Correlations}

$\varepsilon_{\mathrm{g}}, d_{\mathrm{BM}}$, and $K_{\mathrm{L}} S$ depend on the sparger-impeller geometry, agitation intensity, and liquid phase properties. Therefore, extensive work has been done to develop such correlations [46]. Accordingly, a variety of correlations for predicting gas holdup $[35,58-61]$, bubble diameter $[35,62,63]$, and volumetric mass transfer coefficient [64-68] have been reported. The most commonly cited correlations for $d_{\mathrm{BM}}, \varepsilon_{\mathrm{g}}$, and $K_{\mathrm{L}} S$ by Calderbank [35], Loiseau et al. [58], and Yoshida et al. [64], are shown in Eqs. (26)-(28). Hence, depending on the system parameters the experimental hydrodynamic performance of the reactor may be verified with theoretical predictions of $d_{\mathrm{BM}}, \varepsilon_{\mathrm{g}}$, and $K_{\mathrm{L}} S$ as well for validation.

$$
\begin{aligned}
& d_{\mathrm{BM}}=4.15\left[\frac{\sigma^{0.6}}{\left(P_{\mathrm{c}} / V\right)^{0.4} \rho_{\mathrm{L}}^{0.2}}\right] \varepsilon_{\mathrm{g}}^{0.5}+0.0009 \\
& \varepsilon_{\mathrm{g}}=0.011 v_{\mathrm{g}}^{0.36} \sigma^{-0.36} \mu^{-0.056}\left(\frac{P_{0}}{V}+\frac{P_{\mathrm{c}}}{V}\right)^{0.27} \\
& K_{\mathrm{L}} S=1.1\left(N^{3} D^{2}\right)^{2 / 3} v_{\mathrm{g}}^{2 / 3}
\end{aligned}
$$

\subsection{Instrumental Techniques}

In addition to the theoretical methods, experimental methods are available for estimation of $d_{\mathrm{BM}}, S$, and $K_{\mathrm{L}} S$. Image analysis techniques are used for the estimation of $d_{\mathrm{BM}}$, which may also be further correlated with $\varepsilon_{\mathrm{g}}$ to obtain $S$ [69]. Image analysis involves a combination of bubble capture cell, a microscope, and a CCD camera. The illumination source is positioned opposite of the camera and cell. 1000-3000 bubble samples are measured for determination of the mean bubble diameter. For the measurement of $S$ in gas liquid reactions, commonly used methods include light scattering techniques and chemical methods. The light scattering method can be used in systems where gas is in the dispersed phase $[35,46,70,71]$. In the chemical method, a gas liquid reaction system with known kinetics is considered [72]. The interfacial area $(S)$ may be estimated from absorption rates if the parameters like diffusivity and rate constant are known. The most commonly used technique for $K_{\mathrm{L}} S$ measurements in gas liquid reactions is the dynamic gas absorption method $[18,46,69,73]$. In this method, a pure gas is introduced into the liquid at $t=0$, and the concentration of the dissolved gas in the liquid phase $\left(A_{\mathrm{L}}\right)$ is measured as a function of time. An FTIR probe may also be incorporated in the reactor for investigations leading to in situ mechanistic investigation studies [74-77]. The reactor system may be interfaced through software for continuous data logging for recording history of different parametric profiles like the concentration $\left(C_{\mathrm{RSH}}\right)$, the temperature $(T)$, the pressure $\left(P_{\mathrm{t}}\right)$, the volumetric mass transfer coefficient $\left(K_{\mathrm{L}} S\right)$, the mean bubble size $\left(d_{\mathrm{BM}}\right)$, and the reactant, intermediate, and product component profiles. These recorded profiles can be extremely helpful in data analysis for the determination of kinetic parameters and mechanistic pathways.

\subsection{Industrial Reactor Performance}

Experimental evaluation and commercial performance has confirmed optimum catalyst dosage to be around $200 \mathrm{ppm}$ $[30,31]$. Since the power consumption of nonstirred systems is negligible, they are preferable in industrial flow reactors. The air flow rate is kept $200 \%$ higher than the stoichiometric requirement to ensure excess availability of oxygen. At the same time, $\mathrm{O}^{\mathrm{i}}$ level may be increased by operating the oxidizer at 5-7 atm pressure. However, $z_{\mathrm{L}}$ may be 5-50 times higher as compared to the well stirred systems. The presence of significant catalyst dosage, elevated operating temperatures, and much higher $z_{\mathrm{L}}$ values in industrial reactors, raises $\gamma(\gamma>2)$, indicating the reactions to happen in the film instead of the bulk. Therefore, for an industrial reactor, a packed bed contactor is preferred. Simulations showed approximately $20 \mathrm{~min}$ as the required residence time in industrial reactors, which was validated by industrial performance [31]. Having determined the kinetic parameters in a laboratory scale chemical reactor, the industrial performance may be predicted with reasonable accuracy [16] by Eq. (29) using the residence time distribution (RTD) curves pertaining to the industrial reactor hydrodynamics.

$C_{\mathrm{RSH}}^{\mathrm{pre}}=C_{\mathrm{RSH}}^{\mathrm{o}} \sum_{j=1}^{m} e^{-k_{\text {cat }} t_{j}} E\left(t_{j}\right) \Delta t$ 


\section{Conclusions}

Thiols in liquefied petroleum gas are undesirable due to their odor and corrosive nature. Conversion of thiols to less deleterious disulphides is termed as sweetening which is achieved in an oxidizer. The design of an oxidizer in a LPG treatment unit requires studies on thiol oxidation kinetics. This review paper analyses the steps involved in designing a suitable laboratory reactor which can determine true kinetics of oxidation reaction of thiols. It is known that sweetening reactions are inherently slow. Hence, the reaction happens both in film and the bulk. The transport of oxygen from gas phase to liquid phase is controlled by liquid film resistance. To be able to determine the true kinetics representing industrial conditions, it is necessary to establish hydrodynamics which ensures maximum transport of oxygen to the bulk. The problem has been analyzed from the hydrodynamics point of view and an overall rate expression based on gas liquid reaction concept has been developed. Based on this analysis an agitated sparged semi-batch reactor with suitable dimensions has been recommended for thiol oxidation kinetics studies. This design is capable of generating small sized bubbles, assisted by high stirring, ensuring required hydrodynamic conditions essential for maximum transport of oxygen to the liquid bulk. Although the paper focuses on sweetening kinetics however, the understanding gained from this review is applicable to any gas-liquid reaction system of a similar nature.

\section{Acknowledgements}

The CSIR-IIP authors are thankful to Dr. S. M. Nanoti, Head of the Refining Technology Division at CSIR-IIP for his continuous encouragement to work in the area of reaction kinetics. Sudip K. Ganguly expresses his gratitude to Dr B. D. Kulkarni (CSIR-NCL, Pune), Prof. V. G. Gaikar (ICT, Mumbai), Prof. I. M. Mishra (IITRoorkee), Dr V. V. Ranade (CSIR-NCL, Pune), Dr P. D. Vaidya (ICT, Mumbai), and Dr A. Kulkarni (CSIR-NCL, Pune) for useful technical discussions on gasliquid-reactor design aspects. He also appreciates the inputs of our APST graduate student at CSIR-IIP, Shri Anshul Sharma (AS) and Shri Sishir V. Singh (SVS), an undergraduate student trainee from Chemical Engineering Department, R. V. Engineering College, Bengaluru, during technical discussions on mass transfer aspects of gas-liquid reactions. The authors are also thankful to CSIR for providing funds for this CSC-0117/ 10: 12th Five-year-Plan project.

The authors have declared no conflict of interests.

\section{Symbols used}

\begin{tabular}{|c|c|c|}
\hline$a_{1}, b_{1}, c_{1}$ & {$[-]$} & $\begin{array}{l}\text { coefficients of polynomial in } \\
\text { Eq. (24) }\end{array}$ \\
\hline$b$ & {$[\mathrm{~m}]$} & blade height \\
\hline$A_{\mathrm{L}}$ & {$\left[\mathrm{mol} \mathrm{L}^{-1}\right]$} & $\begin{array}{l}\text { concentration of } \mathrm{A} \text { in the bulk } \\
\text { liquid }\end{array}$ \\
\hline$B$ & {$[\mathrm{~m}]$} & baffle width \\
\hline$[\text { cat }]_{\text {tot }}$ & {$\left[\mathrm{mol} \mathrm{L}^{-1}\right]$} & CoPcS catalyst concentration \\
\hline c & {$[\mathrm{m}]$} & height of the sparger \\
\hline C & {$\left[\mathrm{mol} \mathrm{L}^{-1}\right]$} & concentration \\
\hline$C_{\mathrm{L}}$ & {$[\mathrm{m}]$} & height of the impeller \\
\hline$\left[\mathrm{C}_{4} \mathrm{H}_{9} \mathrm{SH}\right]$ & {$\left[\mathrm{mol} \mathrm{L}^{-1}\right]$} & $\begin{array}{l}\text { 1-butanethiol concentration in rate } \\
\text { Eq. (4) }\end{array}$ \\
\hline$d$ & {$[\mathrm{~m}]$} & impeller diameter \\
\hline$d_{\mathrm{BM}}$ & {$[\mathrm{m}]$} & mean bubble diameter \\
\hline$D$ & {$[\mathrm{~m}]$} & reactor diameter \\
\hline$D_{T}$ & {$\left[\mathrm{~m}^{2} \mathrm{~h}^{-1}\right]$} & diffusivity of thiols \\
\hline$E(t)$ & {$\left[\mathrm{min}^{-1}\right]$} & $\begin{array}{l}\text { residence time distribution } \\
\text { function }\end{array}$ \\
\hline$F$ & {$\left[\mathrm{~mol} \mathrm{~min} \mathrm{~m}^{-1}\right]$} & molar flow rate \\
\hline$H$ & {$\left[\mathrm{~m}^{3} \mathrm{~atm} \mathrm{kmol}{ }^{-1}\right]$} & Henry's coefficient \\
\hline$H_{\mathrm{L}}$ & {$[\mathrm{m}]$} & $\begin{array}{l}\text { height of liquid in the reactor } \\
\text { vessel }\end{array}$ \\
\hline$k_{2}$ & {$\left[\mathrm{~L} \mathrm{~mol}^{-1} \min ^{-1}\right]$} & $\begin{array}{l}\text { forward rate constant of first linear } \\
\text { adduct formation step during } \\
\text { production of thiol radicals }\end{array}$ \\
\hline$k_{-2}$ & {$\left[\mathrm{~min}^{-1}\right]$} & $\begin{array}{l}\text { backward rate constant of first } \\
\text { linear adduct formation step } \\
\text { during production of thiol radicals }\end{array}$ \\
\hline$k_{3}$ & {$\left[\mathrm{~L} \mathrm{~mol}^{-1} \min ^{-1}\right]$} & $\begin{array}{l}\text { forward rate constant of the second } \\
\text { linear adduct formation step } \\
\text { during production of thiol radicals }\end{array}$ \\
\hline$k_{-3}$ & {$\left[\min ^{-1}\right]$} & $\begin{array}{l}\text { backward rate constant of the } \\
\text { second linear adduct formation } \\
\text { step during production of thiol } \\
\text { radicals }\end{array}$ \\
\hline$k_{4}$ & {$\left[\mathrm{~min}^{-1}\right]$} & $\begin{array}{l}\text { rate constant of thiol radical } \\
\text { formation step }\end{array}$ \\
\hline
\end{tabular}




\begin{tabular}{|c|c|c|}
\hline$k_{\text {cat }}$ & {$\left[\mathrm{min}^{-1}\right]$} & effective catalytic rate constant \\
\hline$k_{\text {eff }}$ & {$\left[\mathrm{L} \mathrm{mol}^{-1} \min ^{-1}\right]$} & effective rate constant \\
\hline$k_{\mathrm{I}}^{1}$ & {$\left[\mathrm{~L} \mathrm{~mol}^{-1} \min ^{-1}\right]$} & rate constant as in Eq. (5) \\
\hline$K_{\mathrm{L}}$ & {$\left[\mathrm{m} \mathrm{h}^{-1}\right]$} & liquid side mass transfer coefficient \\
\hline$K_{\mathrm{M}}$ & {$\left[\mathrm{mol} \mathrm{L}^{-1}\right]$} & Michaelis-Menten constant \\
\hline$N_{\mathrm{RSH}}$ & {$[\mathrm{mol}]$} & $\begin{array}{l}\text { moles of thiols in the semi-batch } \\
\text { reactor }\end{array}$ \\
\hline$N$ & {$\left[\min ^{-1}\right]$} & impeller speed \\
\hline$N_{\mathrm{p}}$ & {$[-]$} & power number \\
\hline$N_{\mathrm{c}}$ & {$\left[\min ^{-1}\right]$} & critical impeller speed \\
\hline $\mathrm{O}$ & {$\left[\mathrm{mol} \mathrm{L}^{-1}\right]$} & oxygen concentration in film \\
\hline$\left[\mathrm{O}_{2}\right]$ & {$\left[\mathrm{mol} \mathrm{L}^{-1}\right]$} & $\begin{array}{l}\text { oxygen concentration in rate } \\
\text { Eq. (4) }\end{array}$ \\
\hline $\mathrm{O}^{\mathrm{G}}$ & {$\left[\mathrm{mol} \mathrm{L}^{-1}\right]$} & oxygen concentration in gas phase \\
\hline $\mathrm{O}^{\mathrm{i}}$ & {$\left[\mathrm{mol} \mathrm{L}^{-1}\right]$} & $\begin{array}{l}\text { oxygen concentration at the gas } \\
\text { liquid interface }\end{array}$ \\
\hline $\mathrm{O}^{\mathrm{L}}$ & {$\left[\mathrm{mol} \mathrm{L}^{-1}\right]$} & $\begin{array}{l}\text { oxygen concentration in liquid } \\
\text { phase }\end{array}$ \\
\hline$p_{\mathrm{O}_{2}}$ & [atm] & partial pressure of oxygen \\
\hline$P_{\mathrm{c}}$ & {$[\mathrm{W}]$} & $\begin{array}{l}\text { power requirement in sparged } \\
\text { systems }\end{array}$ \\
\hline$P_{\mathrm{o}}$ & {$[\mathrm{W}]$} & $\begin{array}{l}\text { power requirement in ungassed } \\
\text { systems }\end{array}$ \\
\hline$P_{\mathrm{t}}$ & [atm] & total pressure \\
\hline Q & {$\left[\mathrm{kmolh}^{-1}\right]$} & mercaptan oxidation rate \\
\hline$Q_{\mathrm{F}}$ & {$\left[\mathrm{kmolh}^{-1}\right]$} & molar airflowrate \\
\hline$Q_{\mathrm{G}}$ & {$\left[\mathrm{m}^{3} \mathrm{~s}^{-1}\right]$} & volumetric gas flowrate \\
\hline$-r_{\mathrm{RSH}}$ & {$\left[\mathrm{mol} \mathrm{L}^{-1} \min ^{-1}\right]$} & rate of thiol disappearance \\
\hline$R(t)$ & {$\left[\mathrm{mol} \mathrm{L}^{-1} \min ^{-1}\right]$} & overall reaction rate \\
\hline$s$ & {$[\mathrm{~m}]$} & sparger diameter \\
\hline$S$ & {$\left[\mathrm{~m}^{2} \mathrm{~m}^{-3}\right]$} & $\begin{array}{l}\text { interfacial area per unit volume of } \\
\text { the reactor }\end{array}$ \\
\hline$t$ & {$[\mathrm{~min}]$} & experimental time \\
\hline$t_{j}$ & {$[\mathrm{~min}]$} & $\begin{array}{l}j \text { th time element of the residence } \\
\text { time distribution curve }\end{array}$ \\
\hline$T$ & {$[\mathrm{~K}]$} & temperature \\
\hline$V$ & {$[\mathrm{~L}]$} & $\begin{array}{l}\text { volume of liquid phase in the } \\
\text { reactor }\end{array}$ \\
\hline$v_{\mathrm{g}}$ & {$\left[\mathrm{m} \mathrm{s}^{-1}\right]$} & superficial gas velocity \\
\hline$v_{\mathrm{t}}$ & {$\left[\mathrm{m} \mathrm{s}^{-1}\right]$} & terminal gas velocity \\
\hline$z_{\mathrm{L}}$ & {$[\mathrm{m}]$} & film thickness \\
\hline
\end{tabular}

Greek symbols

$\begin{array}{lll}\varepsilon_{\mathrm{g}} & {[-]} & \text { gas holdup } \\ \gamma & {[-]} & \text { Hatta number } \\ \Delta t & {[\mathrm{~min}]} & \text { time interval } \\ \rho_{\mathrm{L}} & {\left[\mathrm{kg} \mathrm{m}^{-3}\right]} & \text { liquid density } \\ \mu & {\left[\mathrm{kg} \mathrm{m}^{-1} \mathrm{~s}^{-1}\right]} & \text { liquid viscosity } \\ \sigma & {\left[\mathrm{N} \mathrm{m}^{-1}\right]} & \text { surface tension }\end{array}$

\section{Sub- and superscripts}

$\begin{array}{ll}0 & \text { initial } \\ \text { i } & \text { air water interface } \\ \text { in } & \text { in to the reactor } \\ \text { L } & \text { bulk liquid } \\ \text { out } & \text { out of the reactor } \\ \text { pre } & \text { predicted } \\ \text { RSH } & \text { thiol }\end{array}$

\section{References}

[1] S. Prakash, Refining Processes Handbook, Gulf Professional Publishing, Burlington, MA 2003.

[2] R. A. Meyers, Handbook of Petroleum Refining Processes, 3rd ed., McGraw-Hill, New York 2004.

[3] S. Langè, L. A. Pellegrini, S. Moioli, B. Picutti, P. Vergani, Ind. Eng. Chem. Res. 2013, 52 (5), 2015-2031.

[4] S. Moioli, L. A. Pellegrini, B. Picutti, P. Vergani, Ind. Eng. Chem. Res. 2013, 52 (5), 2056-2065.

[5] G. D. Hobson, W. Pohl, Modern Petroleum Technology, Applied Science Publishers, London 1975.

[6] B. Basu, S. Satapathy, A. K. Bhatnagar, Catal. Rev. Sci. Eng. 1993, 35 (4), 571-609.

[7] Z. Mallaki, F. Farhadi, Hydrocarbon Proc. 2009, 88 (3), $48-54$.

[8] A. Jain, N. Rathi, S. K. Ganguly, Pet. Sci. Technol. 2012, 30 (23), 2494-2503.

[9] S. K. Ganguly, A. Jain, N. Rathi, Pet. Sci. Technol. 2013, 31 (4), 428-437.

[10] S. K. Ganguly, N. Rathi, A. Jain, Pet. Sci. Technol. 2013, 31 (12), 1283-1293.

[11] T. J. Wallace, A. Schriesheim, H. Hurwitz, M. B. Glaser, Ind. Eng. Chem. Process Des. Dev. 1964, 3 (2), 237-241.

[12] A. B. Sorokin, Chem. Rev. 2013, 113 (10), 8152-8191.

[13] B. Sain, S. N. Puri, G. Das, B. P. Balodi, S. Kumar, A. Kumar, V. K. Kapoor, V. K. Bhatia, T. S. R. P. Rao, G. P. Rai, US Patent 6740 619, 2004.

[14] B. Sain, S. N. Puri, G. Das, B. P. Balodi, S. Kumar, A. Kumar, V. K. Kapoor, V. K. Bhatia, T. S. R. P. Rao, G. P. Rai, GB Patent 2371 300, 2004.

[15] G. Das, B. Sain, S. Kumar, G. Muralidhar, M. O. Garg, Catal. Today 2009, 141 (1-2), 152-156.

[16] S. K. Ganguly, G. Das, S. Kumar, B. Sain, M. O. Garg, Hydrocarbon Proc. 2013, 92 (6), 77-81.

[17] P. V. Danckwerts, Gas-Liquid Reactions, McGraw-Hill, New York 1970.

[18] L. K. Doraiswamy, M. M. Sharma, Heterogeneous Reactions: Analysis, Examples, and Reactor Design. 2. Fluid-Fluid-Solid Reactions, Wiley-Interscience, New York 1983.

[19] O. Levenspiel, Chemical Reaction Engineering, 3rd ed., John Wiley and Sons, New York 1999.

[20] J. G. Van de Vusse, Chem. Eng. Sci. 1958, 8 (1-2), 72-80.

[21] A. Leitao, A. Rodrigues, Chem. Eng. Sci. 1989, 44 (5), 1245-1253.

[22] D. Xia, Q. Zhu, Y. Su, J. Qian, Fuel Sci. Tech. Int. 1996, 14 (9), 1205-1218.

[23] M. R. Ehsani, P. Mirjani, A. R. Sofadoost, IJCRE 2013, 11 (1), 1-12.

[24] W. K. Lewis, W. G. Whitman, Ind. Eng. Chem. 1924, 16 (12), 1215-1220.

[25] S. K. Pal, M. M. Sharma, Ind. Eng. Chem. Process Des. Dev. 1982, 21 (2), 351-353.

[26] D. Xia, Y. Su, J. Qian, Ind. Eng. Chem. Res. 1995, 34 (6), 2001-2005.

[27] D. Xia, Y. Su, J. Qian, Ind. Eng. Chem. Res. 1999, 38 (4), 1291-1294. 
[28] S. K. Ganguly, G. Das, B. Mohanty, R. Bhargava, S. Dawra, Pet. Sci. Technol. 2010, 28 (13), 1-10.

[29] S. K. Ganguly, G. Das, B. Sain, in Proceedings of 2nd Conf. on Advances in Chemical Engineering, (Eds: P. K. Bajpai, H. Bhunai), Macmillan Press, New Delhi 2011.

[30] S. K. Ganguly, G. Das, S. Kumar, B. Sain, M. O. Garg, Catal. Today 2012, 198 (1), 246-251.

[31] S. K. Ganguly, G. Das, S. Kumar, B. Sain, M. O. Garg, Chem. Eng. Trans. 2013, 32, 661-666.

[32] M. R. Ehsani, A. R. Safadoost, R. Avazzadeh, Iran. J. Chem. Chem. Eng. 2013, 32 (2), 71-80.

[33] R. E. Treybal, Mass Transfer Operations, McGraw-Hill, New York 1980.

[34] C. M. Cooper, G. A. Fernstrom, S. A. Miller, Ind. Eng. Chem. 1944, 36 (6), 504-509.

[35] P. H. Calderbank, Trans. IChemE. 1958, 36, 443-460.

[36] B. J. Michell, S. A. Miller, AIChE J. 1962, 8 (2), 262-265.

[37] D. N. Miller, AIChE J 1974, 20 (3), 445-53.

[38] I. T. M. Hassan, C. W. Robinson, AIChE J. 1977, 23 (1), $48-55$.

[39] H. T. Loung, B. Volesky, AIChE J 1979, 25 (5), 893-895.

[40] G. A. Hughmark, Ind. Eng. Chem. Process Des. Dev. 1980, 19 (4), 638-641.

[41] V. B. Rewatkar, J. B. Joshi, Chem. Eng. Technol. 1991, 14 (6), 333-347.

[42] A. Paglianti, K. Takenaka, W. Bujalski, AIChE J. 2001, 47 (12), 2673-2683.

[43] W. L. McCabe, J. C. Smith, P. Harriott, Unit Operations of Chemical Engineering, 6th ed., McGraw-Hill, Boston 2001.

[44] A. W. Nienow, D. Miles, Ind. Eng. Chem. Process Des. Dev. 1971, 10 (1), 41-43.

[45] J. G. Van de Vusse, Chem. Eng. Sci. 1961, 16 (1-2), 21-30.

[46] P. A. Ramachandran, R. B. Chaudhuri, Three Phase Catalytic Reactors, Gordon and Breach Science Publishers, New York 1983.

[47] V. B. Rewatkar, J. B. Joshi, Can. J. Chem. Eng. 1993, 71 (2), 278-291.

[48] D. Chakraborty, G. S. R. Krishna, S. Chakraborty, B. C. Meikap, Ind. Eng. Chem. Res. 2009, 48 (24), 11225-11229.

[49] S. Nagata, Mixing: Principles and Applications, John Wiley and Sons, New York 1975.

[50] V. B. Rewatkar, A. J. Deshpande, A. B. Pandit, J. B. Joshi, Can. J. Chem. Eng. 1993, 71(2), 226-237.

[51] A. Bakker, H. E. A. Van den Akker, Chem. Eng. Res. Des. 1994, 72 (Part A), 573-582.

[52] D. Birch, N. Ahmed, Trans IChemE. 1997, 75 (Part A), 487-496.

[53] R. Sardeing, J. Aubin, M. Poux, C. Xuereb, Trans. IChemE. 2004, 82 (A9), 1161-1168.
[54] F. A. Holland, F. S. Chapman, Liquid Mixing and Processing in Stirred Tanks, Reinhold Publishing Corporation, New York 1966.

[55] V. B. Rewatkar, J. B. Joshi, Chem. Eng. Technol. 1991, 14 (6), 386-393.

[56] J. H. Rushton, E. W. Costich, H. J. Everett, Chem. Eng. Prog. 1950, 46 (8), 395-404.

[57] J. H. Rushton, E. W. Costich, H. J. Everett, Chem. Eng. Prog. 1950, 46 (8), 467-476.

[58] B. Loiseau, N. Midoux, J. C. Charpentier, AIChE J. 1977, 23 (6), 931-935.

[59] J. M. Smith, K. V. Riet, J. C. Middleton, in Proceedings of the 2nd European Conference on Mixing, BHRA, Cranfield 1977.

[60] M. M. C. G.Warmoeskerken, J. M. Smith, in Proceedings of the 7th International Congress of Chemical Engineering, CHISA, Prague 1981.

[61] R. Parthasarthy, N. Ahmed, in Proceedings of 7th European Congress on Mixing, Brugge 1991.

[62] R. Kumar, N. R. Kuloor, Adv. Chem. Eng. 1970, 8, 256-368.

[63] M. Moo-Young, H. W. Blanch, Adv. Biochem. Eng. 1981, 19, $1-69$.

[64] F. Yoshida, A. Ideka, S. Imakawa, Y. Miura, Ind. Eng. Chem. 1960, 52 (5), 435-438.

[65] J. M. Smith, M. M. C. G. Warmoeskerken, in Proceedings of 5th European Conference on Mixing, Würzburg 1985.

[66] H. Wu, Chem. Eng. Sci. 1995, 50 (17), 2801-2811.

[67] Y. Zhu, P. C. Bandopadhayay, J. Wu, J. Chem. Eng. Japan 2001, 34 (5), 579-584.

[68] A. A. Yawalkar, A. B. M. Heesink, G. F. Versteeg, V. G. Pangarkar, Can. J. Chem. Eng. 2002, 80, 840-848.

[69] S. V. Singh, B.Tech. Thesis, R. V. College of Engineering, Bengaluru 2011.

[70] T. Rieth, Brit. Chem. Eng. 1970, 15 (2), 1559-1563.

[71] J. Landau, H. G. Gomma, A. M. Al Taweel, Trans. IChemE. 1977, 55, 212-215.

[72] M. M. Sharma, P. V. Danckwerts, Brit. Chem. Eng. 1970, 15 (4), 522-528.

[73] K. V. Rieth, Ind. Eng. Chem. Process Des. Dev. 1979, 18 (3), 357-364.

[74] G. M. Hamminga, G. Mul, J. A. Moulijn, Chem. Eng. Sci. 2004, 59 (22-23), 5479-5485.

[75] A. Pintara, R. Malaceaa, C. Pinela, G. Fogassya, M. Besson, Appl. Catal. A. 2004, 264, 1-12.

[76] J. M. Rowley, E. B. Lobkovsky, G. W. Codes, J. Am. Chem. Soc. 2007, 129 (16), 4948-4960.

[77] W. Z. Xu, P. A. Charpentier, Ind. Eng. Chem. Res. 2009, 48 (3), 1384-1397. 